\title{
Pinceladas de la medicina chilena en el siglo XIX. A 200 años de la Independencia*
}

\author{
Dr. RICARDO ESPINOZA G. ${ }^{1}$ \\ ' Facultad de Medicina Universidad de los Andes, Santiago, Chile.
}

Some aspects of Chilean medicine in the 19th century.
200 years after Independence

Comentar algunos aspectos de la medicina chilena en el siglo XIX significa exponer los primeros pasos enmarcados en los orígenes de esta nación, de los variados aspectos que tocan relación con esta ciencia y este arte. Comprendemos que la medicina y sus alcances van mucho más allá del binomio que conforma un paciente y el médico y que si bien éste representa su núcleo más íntimo, no lo agota. Por tanto, los comentarios significan también revisar la relación de la medicina con la sociedad y la cultura, la formación médica, el ejercicio mismo de la profesión y sus regulaciones.

Es comprensible que lo sucedido en la época post-hispánica no constituye una improvisación sino que es el resultado del desarrollo alcanzado en épocas previas, al que se suman los elementos renovadores de la nueva etapa, en este caso, ligados a la emancipación de la corona española y a la apertura que ello significó. Todo, sin dejar de tener presente que en el referido siglo, la renovación científica mundial también impactó en estas latitudes, aunque lenta y tardíamente.

En este recorrido no se revisarán los aspectos relacionados con la medicina militar, que si bien importantes y frecuentes en una época de confrontaciones, constituyen un capítulo aparte. Además, los comentarios estarán centrados, fundamentalmente, en los hechos acontecidos en Santiago.

\section{Medicina chilena a fines de la época hispánica}

Tal como sucedió en la Europa medieval, los orígenes de la medicina chilena estuvieron íntimamente ligados a las órdenes religiosas. Aún cuando no existe documentación que lo avale, se tiene por cierto que el primer hospital en Chile, Hospital del Socorro, lo fundó Pedro de Valdivia, y era administrado por el Cabildo'. Más, desde 1617 fue encomendado a los hermanos de la Orden religiosa de la Caridad de los Hermanos Hospitalarios, los "padres capachos", tarea que cumplieron hasta 1823. Era costumbre, por tanto, que junto al hospital se ubicase también el convento y la capilla. Además, era habitual que los mismos frailes cultivaran la tierra aledaña para obtener los recursos vegetales que constituían la base de la farmacopea de la época. Sin embargo, la botica de este hospital siempre fue notoriamente inferior a la de los jesuitas, que sobrepasaba las 1.000 preparaciones.

Este hospital, posteriormente rebautizado como San Juan de Dios, se ubicó inicialmente entre San Isidro y Carmen, al sur de la Cañada, y fue por años, el único hospital en Santiago. Después se trasladó a la calle San Francisco, donde permaneció hasta su demolición en el año 1944. Reconstruido y ampliado en numerosas ocasiones, con motivo de los

\footnotetext{
* Recibido el 23 de Agosto de 2010 y aceptado para publicación el 17 de Septiembre de 2010.

Correspondencia: Dr Ricardo Espinoza G.

San Carlos de Apoquindo 2200, Santiago, Chile. Fax: 5622141752.

E/mail: respinoza@uandes.cl
} 
frecuentes terremotos, era, sin embargo, a fines del siglo XVIII, un edificio que adolecía de muchísimos defectos en infraestructura y en sus prácticas. Para ese entonces contaba con unas 100 camas. Sin embargo, se repetían las condiciones de hacinamiento, insuficiente ventilación y mala iluminación. Todo el ambiente denotaba falta de higiene y baja salubridad. Las salas se dividían ya sea para pacientes varones o para mujeres, por separado fuesen españoles o nativos. Los lechos eran camastros de madera con cueros, y las sábanas eran de hilo para los españoles y de tocuyo para los indígenas. La ordenación de estas camas prescindía de la naturaleza de las enfermedades, e incluso, muchas veces acogían a más de un enfermo ${ }^{2}$. Recordemos que todo ello ocurría en una época previa al conocimiento de los microorganismos y de todas las medidas de asepsia que sólo llegarían un siglo después.

En 1772 había abierto sus puertas el Real Hospital de San Francisco de Borja, en la Alameda, entre las calles Castro y Dieciocho. Contaba, inicialmente, con 20 camas destinadas a la atención de mujeres. Estos dos centros, sin embargo, eran claramente insuficientes; Santiago, a comienzos del siglo contaba con una población cercana a las 24.000 personas y existían sólo unos 15 médicos y cirujanos. Los sueldos de éstos variaban entre 150 pesos anuales para los primeros y entre 80 y 100 para los segundos; el sueldo del gobernador alcanzaba los 10.000 pesos al año. Para la mantención de los hospitales se contaba con aportes fiscales y las limosnas, más lo que producían los frailes y sus propiedades; sin embargo, era crónica su situación deficitaria ${ }^{2}$.

El siglo XIX comenzaba con tres destacados médicos locales, Fray Rosauro Acuña, el flebótomo Pedro Morán e Isidro Zapata. Los extranjeros de destacada actuación y mayor legado fueron el español Manuel Grajales y Nataniel Cox, inglés. Debieron enfrentar los difíciles tiempos de la Patria Vieja y sufrir persecuciones y muchas veces destierro. Sin embargo, todos prestaron esforzados trabajos profesionales a realistas y patriotas, formando parte, algunos de ellos, del Ejército Libertador. Los soldados eran atendidos en los mencionados hospitales, en salas acomodadas para tal efecto.

Con todo, la incipiente medicina chilena, estaba muy lejana de los centros europeos donde se develaba el conocimiento científico moderno; aquí se batallaba contra la insalubridad ambiental y la escasez de agua potable; a las aguas del río Mapocho se las indicaba como "corruptas y perniciosas". Todo ello contribuía a que existieran frecuentes epidemias de disentería y "chavalongo" (tifus), las que se sumaban a la gripe y a la temible viruela.

La publicación entre 1812 y 1813, de la Aurora de Chile $^{3}$, editada por Fray Camilo Henríquez, daba cuenta en algunos de sus números de la situación vivida al interior del Hospital San Juan de Dios. Un ejemplo es el extracto aparecido en el No 39 de 1812 , en que se que señala el número de pacientes ingresados y fallecidos por cada sala del hospital, haciendo hincapié en los efectos de la viruela. Más adelante, en el $\mathrm{N}^{\circ} 1$ de enero de 1813 se comenta que: "Continúan los horrorosos estragos de la viruela... nunca, ni cuando carecíamos del gran beneficio de la Vacuna se había visto peste de más malignidad ..." En el No 3 se precisa que en Santiago, "al año vencido de 1812 se habían vacunado 2.729 personas". La vacuna contra la viruela se había comenzado a aplicar en 1765, por el catedrático Domingo Nevin, por entonces a cargo de la Cátedra Prima de Medicina de la Universidad de San Felipe.

Pues bien, a través de la referida publicación y luego otras, podemos conocer, al menos en parte, de las condiciones sanitarias y de salubridad de la época. Destacan como diagnósticos frecuentes al interior de los hospitales, aparte de los ya mencionados, la sífilis y luego se sumaría el de la tuberculosis. También, y como producto de la batallas, eran frecuentes los heridos, especialmente los que requerían una amputación. Pues bien, las muy limitadas condiciones en que se efectuaban los traslados, hacían: "... necesaria la amputación inmediata para salvar al paciente de crueles torturas y una muerte agonizante"4. Por esta razón, las más de las veces, éstas se efectuaban en el mismo campo de batalla.

\section{Los estudios de medicina y los médicos}

La notable escasez de médicos en la época colonial se mantuvo hasta avanzado el siglo XIX. Nos cuenta Cruz-Coke ${ }^{2}$ que primero era la Real Audiencia y el Cabildo de Santiago, y luego fue el mismo gobierno patriota quien regulaba el ejercicio médico, incluidos los aranceles profesionales, situando éstos en niveles extremadamente bajos. Una consulta médica, hacia 1830 equivalía a poco más de 7.000 pesos actuales. Ante el Cabildo se solicitaba autorización para ausentarse de la ciudad donde se tenía licencia para atender. Si a este control se le sumaba la falta de una educación médica de buen nivel, se entendía por qué las condiciones de los médicos eran muy limitadas, motivo de menosprecio social. Algunos aranceles médicos, (considerando que a comienzos del siglo XIX un peso español de plata equivalía a 8 reales), fijados por la Real Audiencia en 1799 y vigentes hasta después de 1831 eran los siguientes: visita simple 4 reales; visita a medianoche 8 reales; operación quirúrgica simple 2 pesos; compuesta, como la amputación de ambas piernas 4 pesos. Las visitas fuera de la ciudad se cobraban según la distancia en leguas a que se encontraba el 
enfermo $^{1,2}$.

Por otra parte, y siguiendo las normas de la corona española, desde 1786 ejercía sus funciones en Chile el Protomedicato, entre cuyas tareas estaba cautelar la salud de los ciudadanos, otorgando los permisos profesionales para ejercer; también velaba por la idoneidad de los hospitales. Con interrupciones, este tribunal pasó a depender de la Universidad de Chile en 1843, siendo el decano de medicina el protomédico del Estado. Dejó de funcionar en 1892. Con todo, esta institución monárquica no pudo responder eficientemente a los desafíos docentes y a la necesaria formación de médicos; sin embargo, sentó las bases para el control del estado en estas materias.

Conscientes de la necesidad de profesionales, ya en 1756 con la apertura de la Cátedra de Medicina de la Real Universidad de San Felipe y prácticas en el Hospital San Juan de Dios se pensó formar médicos en Chile, independientemente de la Universidad de San Marcos en Lima. El primer alumno y primer médico titulado en dicha Universidad fue el fraile Matías del Carmen Verdugo. Sin embargo, al cabo de cinco décadas, sólo se había formado como médico a siete nativos. Un fracaso total de la Universidad en el área médica. Una crónica de la época señalaba que ni aún rogando a algunos jóvenes pobres, dándoles casa y comida gratis, se lograba que se decidiesen por los estudios médicos ${ }^{2}$. La medicina era considerada un arte plebeyo, degradante y que reportaba escasos ingresos.

Todo lo anterior explica que durante la Colonia $\mathrm{y}$ en los primeros años republicanos, los escasos médicos nacionales y los médicos extranjeros residentes, sólo pudieran dar atención a un reducido número de habitantes, habitualmente los de situación más acomodada. Por tanto, una buena parte de la población normalmente recurría a una medicina popular que estaba en manos de yerbateros, "meicas" y chamanes.

Luego, con la Patria Nueva, esta situación se modificó radicalmente, aunque tomó considerable tiempo. José Miguel Carrera fundó el Instituto Nacional y con ello surgieron nuevos intentos por formar una Facultad de Medicina. A la vez, la llegada de numerosos médicos europeos aportó nuevas visiones de la docencia y de los contenidos que debían considerar los programas de estudio. La primera convocatoria data de 1813 , pero no hubo alumnos hasta bastante después. Sólo en 1833 se inscriben los primeros 10, titulándose cuatro de ellos recién en 1842: Javier Tocornal, Luis Ballester, Juan Mackenna y Francisco Rodríguez. Algunos de los restantes fallecieron por infecciones contraídas en el curso de sus estudios ${ }^{2}$. Múltiples factores, en parte por los alumnos y también por las dificultades para conformar las necesarias cátedras, explican el lento desarrollo. Los estudios teóricos se hacían en el Instituto Nacional. Recién en 1843 la naciente Universidad de Chile comenzó a tomar el control de la formación profesional, puesto que hasta entonces las funciones universitarias se habían centrado en las labores académicas.

En este tema mencionaremos una anécdota de cómo, un hecho en apariencia fortuito, contribuyó a cambiar la imagen médica en Chile ${ }^{2,5}$. Contamos que Nataniel Cox, médico inglés, había llegado a Chile. Ello ocurrió en 1814, y producto de una casualidad: venía desde Montevideo a saludar a un amigo. Nos cuenta Reccius ${ }^{5}$ que estando Cox en estas tierras, fue llamado por el capitán Manuel Blanco Encalada para atender a su tío don José Manuel Calvo de Encalada y Recabarren, tercer marqués de Villa Palma, quien padecía de cálculos vesicales. Cox le efectuó, exitosamente, una "operación de la talla vesical", (cistotomía), la primera registrada en el país. Con ello este médico de inmediato adquirió un prestigio y se relacionó con la alta aristocracia, decidió quedarse en Chile y más tarde, incluso, contrajo matrimonio con una criolla. Otras destacadas figuras fueron Lorenzo Sazié y Guillermo Blest. Sazié participó activamente en la docencia. El segundo, en 1826, hizo una presentación sobre el estado de la medicina, adjuntando un renovador plan de estudios médicos. Blest ${ }^{6}$ señalaba: "Así como el poder de una Nación consiste en el número de sus habitantes...y su felicidad en tiempos de paz es graduado en parte por el estado de su salud... es de necesidad que la preservación de las enfermedades sea confiada a personas calificadas... llamar en fin la atención de las autoridades a la reforma del sistema de educación médica".

Estos últimos médicos y varios más, también contrajeron matrimonio con personas de alto nivel social y encumbradas relaciones políticas, con lo que participaron directamente de la naciente alta sociedad. Lograron éxito profesional, económico $\mathrm{y}$, además, desarrollaron labores legislativas en el Congreso. Todo lo anterior se plasmó en un creciente interés porque jóvenes criollos valorasen mejor la profesión y se decidiesen por seguir tales estudios. En la segunda mitad del siglo XIX fue José Joaquín Aguirre una de las figuras más destacadas, quien ejerció en Chile como médico, decano, rector $\mathrm{y}$ legislador.

Por otra parte, la llegada a Chile de sabios como Ignacio Domeyko y Rodolfo Philippi, elevó notablemente el nivel de la enseñanza y permitió sustentar con solidez, los primeros cursos de la pujante escuela de medicina. Poco más tarde se creó la Sociedad Médica de Chile (1869) y en 1872 vio la luz la Revista Médica de Chile, además de contar con los Anales de la Universidad de Chile desde $1846^{6}$. 
Esta labor de formación médica comenzó su consolidación cuando en 1863 se trasladó la Escuela de Medicina a la calle San Francisco, al sur del Hospital San Juan de Dios, la "antigua Escuela", detalladamente retratada por Augusto Orrego Luco en su afamada crónica "Recuerdos de la Escuela", rica en semblanzas de las más destacadas personalidades médicas de la época. De esta forma se transitó, en menos de medio siglo, de un reducido número de profesores y alumnos, a una escuela similar a las europeas de la época, con unos 350 alumnos y prácticamente todas las cátedras.

Volviendo a la anécdota de Cox, presentamos las condiciones en que se desarrollaba esta "operación de la talla", de acuerdo a una manual de la época: "Se debe preparar una mesa sólida, y en su defecto debe emplearse una cómoda". Sigue el texto: "Son necesarios cinco ayudantes; dos para sostener los muslos y las piernas, el tercero para sujetar la espalda, el cuarto, que será el más instruido, tendrá el catéter y levantará las bolsas, y el quinto presentará los instrumentos al profesor"8. No existía la anestesia. En otro párrafo: "Varias vasijas... otra bastante grande que contenga arena o ceniza, destinada a colocarse al pie de la mesa para recibir la sangre y el orín"8. Estas recomendaciones hablan por sí solas.

\section{La consolidación de la segunda mitad del siglo XIX}

En la segunda mitad de siglo XIX, las instituciones se consolidaron y como dijimos, la antigua Escuela de Medicina se estableció en 1863 en el callejón San Francisco, con Vicente Padin como decano. En 1889 se trasladó a la avenida Independencia. Allá, junto al Hospital San Vicente de Paul, en pleno barrio de la Chimba, continuó la tradicional docencia universitaria médica, adoptando este hospital los caracteres del primer hospital docente del país. Los nuevos planes de estudio mantenían la Anatomía, Química, Física, Botánica y Zoología en primer año, Fisiología y Patología en segundo y asistencia a los hospitales desde tercero. Los estudios culminaban con un internado en sexto año. Con un decreto de 1877 se permitió a las mujeres ingresar a la Universidad, y así se tituló Eloísa Díaz Insunza en 1886 como la primera mujer médico en Chile y un año después, Ernestina Pérez Barahona.

Hacia fines del siglo, y bajo la influencia alemana y francesa, comenzó a utilizarse en Chile el estetoscopio y el oftalmoscopio; comenzaron a aplicarse algunas pruebas de química sanguínea y técnicas microscópicas. Los antiguos hospitales coloniales se ampliaron, manteniéndose el San Juan de Dios como el principal en el país. A modo de ejemplo, en 1864 este centro atendió 6.495 pacientes en nueve meses, de los cuales falleció el 19,8\%. Algo similar ocurría en el San Borja, en 1860 allí fueron atendidos, y sólo por cuatro médicos, 6.500 pacientes, con una mortalidad del 17,8\%. Desde 1831 se había ampliado la maternidad de la Casa de Huérfanos, considerando que existía en nuestro país una elevada tasa de natalidad, pero con una sobrecogedoramente alta mortalidad infantil. El doctor Adolfo Murillo lo decía así: "En 1869 de 79.922 bautizados sobrevivieron $30.522 \ldots$ sólo quería dar la alarma por el estado lamentable de la hijiene de nuestras poblaciones i por las cifras desconsoladoras y terribles que alcanzaba la mortalidad" 7 .

Para la atención de enfermos mentales se creó en 1852 la Casa de Orates, en el barrio Yungay, donde llegaron a permanecer internados más de 400 insanos. Su dotación inicial de 30 camas rápidamente se amplió a 100, pero sobrevino “... grado tal de hacinamiento que, a manera de ejemplo prototípico, en una habitación de 3x4 metros dormían 17 enfermos, sin camas y sólo con un poco de paja colocada encima del asfalto del piso" 9 .

Otros notables esfuerzos de privados se concretaron en cuantiosas donaciones que permitieron hacia 1875, cuando Santiago era una ciudad con alrededor de 200.000 habitantes, contar con unas 1.000 camas de hospital sumando las de los antiguos y nuevos centros. Esta población era socorrida por poco más de 20 de los 200 médicos que residían en Chile ${ }^{2}$, quienes otorgaban una renovada atención.

De esta forma, de una medicina muy limitada y de lazaretos, se había transitado en el siglo de la independencia a hospitales más modernos, entre los que se contaba con el tradicional San Juan de Dios y San Borja, y los recientemente edificados San José, del Salvador y el ya mencionado San Vicente ${ }^{10,11}$.

Más, observamos que todos esos grandes esfuerzos debían aún redoblarse en los años venideros, para ir mejorando más y más la atención médica en nuestro país. No faltaron iniciativas ni esfuerzos personales para seguir progresando. Además, las nuevas generaciones de médicos formados en Chile, con frecuencia visitaban centros europeos, aportando a su regreso nuevas visiones y más adelantos.

\section{Referencias}

1. Vicuña Mackenna B. Los médicos de antaño en el Reino de Chile. Editorial Difusión S.A. Santiago, Chile, 1947.

2. Cruz-Coke R. Historia de la medicina chilena. Editorial Andrés Bello. Santiago, Chile, 1995.

3. Aurora de Chile. Periódico Ministerial y Político. 18121813.

4. On gut-shot wounds. N Engl J Med 1812; 1: 344-358. 
5. Reccius A. Esculapio en el Reino de Chile. Empresa Editora Zig-Zag, Santiago, Chile, 1967.

6. Blest CG. Observaciones sobre el estado actual de la medicina en Chile con la propuesta de un plan para su mejora (1926). Rev Med Chile 1983; 111: 350357.

7. Larraín C. La Sociedad Médica de Santiago y el desarrollo histórico de la Medicina en Chile. Imprenta Salesianos, Santiago, Chile, 2002.
8. Orrego Luco A. Recuerdos de la Escuela. Editorial Francisco de Aguirre, S.A. Buenos Aires, Argentina, 1976.

9. Tavernier A. Manual de Cirugía. Madrid, 1830.

10. Puente S. Historia de la cirugía en el Hospital San Francisco de Borja. Rev Chil Cir 2006; 58: 473-478.

11. Núñez H, Osorio C. Arqueología del Hospital San Vicente de Paul. Rev Med Chile 2007; 135: 264-269.

12. Medina E. De Manicomio Nacional a Hospital Psiquiátrico. Rev Chil Neuro-Psiquiatr 2001: 39: 78-81. 